Abstracta Iranica Abstracta Iranica

Revue bibliographique pour le domaine irano-aryen

Volume 31 | 2011

Comptes rendus des publications de 2008

\title{
Sources for the Study of the School of Nisibis (Translated Texts for Historians 50). Liverpool, Liverpool University Press, 2008, 256 p.
}

Florence Jullien

\section{CpenEdition}

1 Journals

Édition électronique

URL : http://journals.openedition.org/abstractairanica/39642

DOI : 10.4000/abstractairanica.39642

ISSN : 1961-960X

Éditeur :

CNRS (UMR 7528 Mondes iraniens et indiens), Éditions de l'IFRI

\section{Édition imprimée}

Date de publication : 15 mai 2011

ISSN : 0240-8910

Référence électronique

Florence Jullien, « Sources for the Study of the School of Nisibis (Translated Texts for Historians 50). Liverpool, Liverpool University Press, 2008, 256 p. », Abstracta Iranica [En ligne], Volume 31 | 2011 document 203, mis en ligne le 11 octobre 2012, consulté le 27 septembre 2020. URL : http:// journals.openedition.org/abstractairanica/39642; DOI : https://doi.org/10.4000/abstractairanica. 39642

Ce document a été généré automatiquement le 27 septembre 2020.

Tous droits réservés 


\section{Sources for the Study of the School of Nisibis (Translated Texts for Historians 50). Liverpool, Liverpool University Press, 2008, 256 p.}

Florence Jullien

La communauté chrétienne de langue syriaque a développé une culture scholastique qui a perduré pendant plusieurs siècles depuis l'Antiquité tardive jusqu'à l'époque médiévale. Tout en se distinguant des académies rabbiniques, les écoles syro-orientales furent des centres innovants qui institutionnalisèrent le cursus studiorum. L'A. s'appuie sur les études d'A. Vööbus, et avant lui de J.-B. Chabot, sur l'école de Nisibe, ses statuts et ses réglementations, pour fournir une synthèse sur le sujet; il y ajoute une traduction en anglais, la première dans cette langue, de la Cause de la fondation des écoles par l'évêque de Hulwan, Barhadbshabba 'Arbaya, agrémentée d'un commentaire. Pour l'édition française du texte, voir le volume 4 de la Patrologia orientalis publié par A. Scher en 1908, p. 316-404.

INDEX

Thèmes : 6.3. Autres religions 
AUTEURS

FLORENCE JULLIEN

EPHE - Paris 